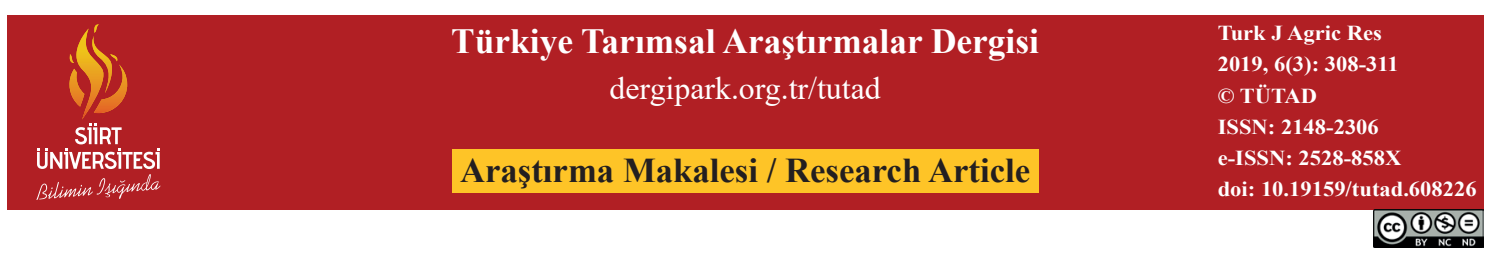

\title{
Cousinia gigantosphaera Rech, f. (Asteraceae-Compositae); Türkiye'nin Güneydoğu Anadolu Bölgesi’nden Yeni Bir Bitki Türü Kaydı
}

\author{
Mehmet FiDAN ${ }^{1 *}$, Süleyman Mesut PINAR², Hüseyin EROĞLU ${ }^{3}$ \\ ${ }^{1}$ Siirt Üniversitesi, Fen Edebiyat Fakültesi, Biyoloji Bölümü, Siirt, TÜRKIYYE \\ ${ }^{2}$ Van Yüzüncü Yıl Üniversitesi, Van Sağllk Yüksekokulu, Beslenme ve Diyetetik Bölümü, Van, TÜRKIYE \\ ${ }^{3}$ Van Yüzüncü Yll Üniversitesi, Fen Fakültesi, Biyoloji Bölümü, Van, TÜRKIYYE
}

\begin{tabular}{|c|c|}
\hline Geliş Tarihi/Received: 21.08 .2019 & Kabul Tarihi/Accepted: 14.11.2019 \\
\hline \multicolumn{2}{|l|}{ ORCID ID (Yazar surasına göre / by author order) } \\
\hline (1D) orcid.org/0000-0002-0255-9727 (D) orcid.org/0000-0002-17 & cid.org/0000-0001-9171-5607 \\
\hline
\end{tabular}

Öz: Türkiye'nin Güneydoğu Anadolu Bölgesi'nde yer alan Şırnak ilinde 2018-2019 yılları arasında Tarım ve Orman Bakanlığı, Doğa Koruma ve Milli Parklar Genel Müdürlüğü kontrolünde "Şırnak İlinin Karasal ve İç Su Ekosistemleri Biyolojik Çeşitlilik ve Envanter İzleme Projesi” yapılmıştır. Bu proje kapsamında yapılan arazi çalışmalarında toplanan Cousinia cinsine ait bazı örneklerin Türkiye'de bulunan taksonlardan farklılık gösterdiği belirlenmiștir. Bu örneklerin detaylı ve karşılaştırmalı teşhisi ile Cousinia gigantosphaera Rech.f olduğu anlaşılmış ve Türkiye'den (Şırnak, Beytüşşebap) ilk defa kayıt altına alınmıştır.

Anahtar Kelimeler: Cousinia, flora, yeni kayıt, Şırnak, Türkiye

\section{Cousinia gigantosphaera Rech, f. (Asteraceae-Compositae); A New Plant Species Record from the Southeastern Anatolia Region of Turkey}

\begin{abstract}
Biodiversity and Inventory Monitoring Project for Terrestrial and Inland Water Ecosystems of Şırnak Province" was conducted between 2018-2019 under the control of Republic of Turkey Ministry of Agriculture and Forestry, Directorate General for Nature Conservation and National Parks in Şırnak Province located in the Southeastern Anatolia Region of Turkey. Within the scope of the project some Cosinia samples were collected in the field and it was determined that these samples differed from other Cousinia taxa in Turkey. With detailed and comparative diagnosis of samples it is understood that these samples belong to Cousinia gigantosphaera Rech.f species and have been recorded for the first time (Şırnak, Beytüşşebap) in Turkey.
\end{abstract}

Keywords: Cousinia, flora, new record, Şırnak, Turkey

\section{Giriş}

Cousinia Cass. Asteraceae (Compositae) familyasında yer alan bir cins olup, dünya genelinde 672 taxon içermekte; Bu taksonların 235 tanesi İran'da doğal yayılış göstermektedir (Rechinger, 1972; Sheidai ve ark., 2006; Ranjbar ve ark., 2012). Avrupa'da tek türle (Moore, 1975) temsil edilen Cousinia cinsinin İran'da 50 seksiyonu bulunmaktadır (Mehregan ve ark., 2003). Türkiye'de ise 26's1 endemik olmak üzere toplam 40 türü bulunmakta ve endemizim oranı \% 65'tir (Anonim, 2019).

Türkiye ve İran'daki takson sayıları ve endemizim durumlarına bağlı olarak cinsin gen merkezinin Doğu Anadolu ve İran olduğu bildirilmiştir (İlçim ve Özçelik, 1997). 
Şırnak ilinin biyolojik çeşitlilik çalışması sırasında, 2018-2019 yılları arasında yazarlar tarafından arazi çalışmaları esnasında toplanan Cousinia cinsine ait örnekler arasında farklı karakterlere sahip, örneklerin teşhisi sırasında daha önce Türkiye'de kayıt altına alınmamış ve tip lokalitesi olarak "Irak: Kürdistan: Süleymaniye" olan bir takson tespit edilmiştir.

Bu çalışmanın amacı Türkiye'de Asteraceae familyasının yer aldığı Türkiye florasının 5 . cildindeki parametrelerin kullanılarak Cousinia cinsine ait yeni bir tür kaydının verilmesidir.

\section{Materyal ve Yöntem}

Araştırma materyalini "Şırnak İlinin Karasal ve İç Su Ekosistemleri Biyolojik Çeşitlilik ve Envanter İzleme Projesi" kapsamında yapılan arazi çalışmalarında, Şırnak ili Beytüşşebap ilçesi kırsalında toplanan Cousinia cinsine ait bazı bitki örnekleri oluşturmaktadır. $\mathrm{Bu}$ bitkilerin teşhisi sırasında Türkiye Florası'nda yer alan hiçbir taksona uymadığg1, Türkiye'de yayılış gösteren mevcut taksonlardan bazı morfolojik farklılıklar gösterdiği tespit edilmiştir. Bu bitki türünün teşhisi için; "Flora of Turkey and the East Aegean Islands" (Huber-Morath, 1975; Davis ve ark., 1988; Güner ve ark., 2000), "Flora Europaea" (Moore, 1975) "Flora Iranica" (Rechinger, 1979), "Flora of Lowland Iraq" (Rechinger, 1964), "Flora of the USSR" (Tscherneva, 1962), "Flora of Palestina" (Post, 1933) ve "Systematics, Phylogeny And Biogeography of Cousinia (Asteraceae)" (Mehregan and Kadereit, 2008) gibi eserlerden yararlanılmıştır. Teşhisimizin doğruluğunu teyit etmek için, toplanan bitki örnekleri herbaryumlarda (VANF Herbarium Catalogue, http://www.omnia.ie/index.php?europ eana_query) yer alan ve teşhisi doğrulanmış herbaryum örnekleri ile karşılaştırılmıştır. Türün morfolojik betimi, daha önce diğer floralarda yapılan betimlere ve yeni toplanan materyale dayanarak hazırlanmıştır. Bu bitki türüne ait tip lokalitesi ve Türkiye'de bu çalışma ile belirlenen yayılıș alanı Şekil 1'de verilmiştir. Teşhis edilen örnekle Van Yüzüncü Y1l Üniversitesi Fen Fakültesi Herbaryumu (VANF) ve Siirt Üniversitesi Flora ve Fauna Merkezi (SUFAF) herbaryumlarında saklanmaktadır.

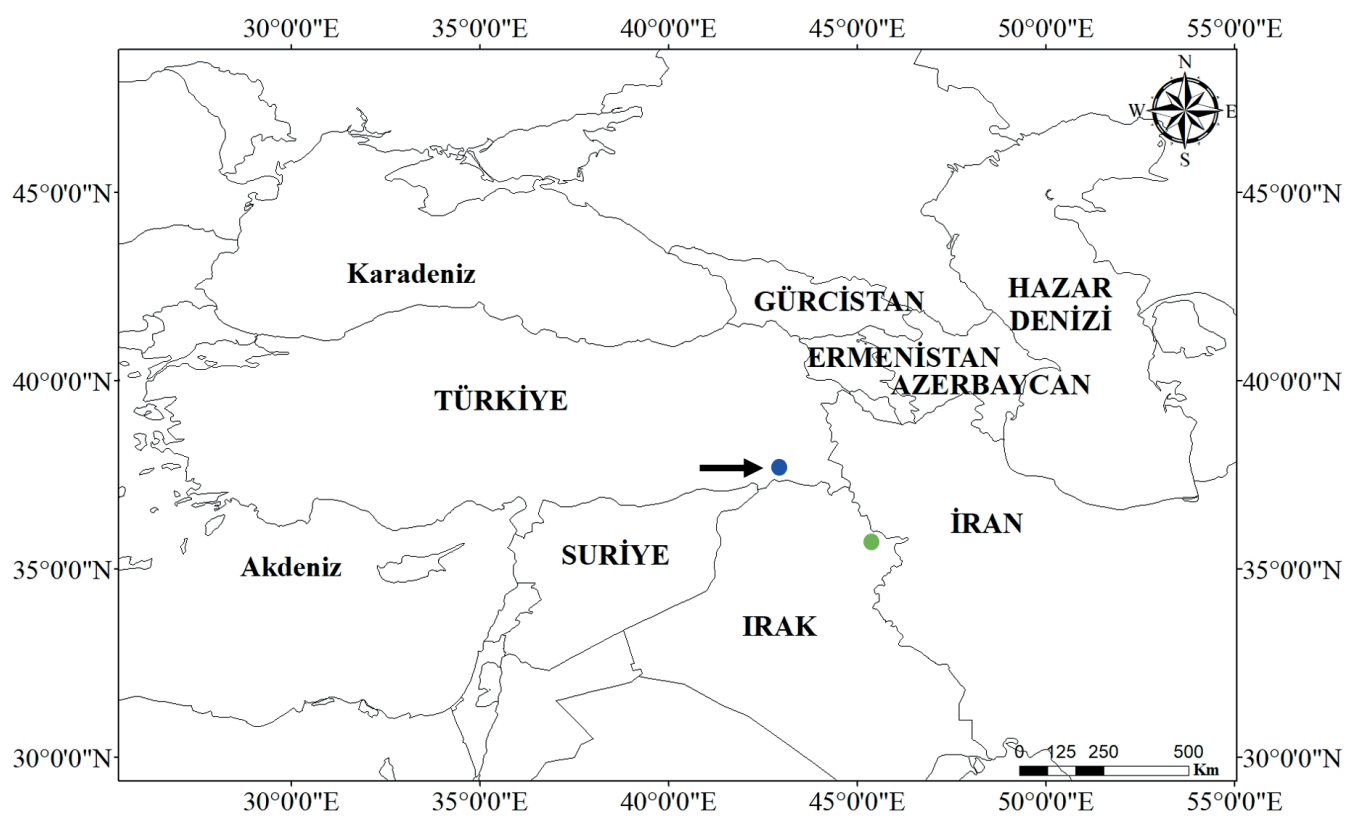

Şekil 1. Cousinia gigantosphaera'nın tip lokalitesi (๑), okla gösterilen türün Türkiye lokalitesi

\section{Bulgular ve Tartışma}

\section{Cousinia gigantosphaera Rech, f. (Şekil 2)}

Bitki 50-80 cm boyunda, araknoid tüylü; gövde genellikle tabandan veya biraz daha üst taraflardan dallanma gösterir. Gövde uç kısımlara kadar yoğun yapraklı ve kanatlı. Yapraklar derimsi yapıda ve her iki tarafi tomentos tüylü. Taban yaprakları obovate, $32 \times 17 \mathrm{~cm}$ kadar büyüyebilirler, kenarları hafif dikenli dişlere sahip. Gövde yaprakları sapsız, yukarı doğru gidildikçe küçülürler, oval eliptik geniş mızrak şeklinde olabilirler, kenarları dikenli loblu ve gövdeye bağlandığı yerlerden aşağı doğru gövde kanadını oluştururlar. En üstteki gövde yaprakları kapitulumun alt kısımlarını örterler. Kapitulumlar uçta ve tekli, 3-4.5 cm 


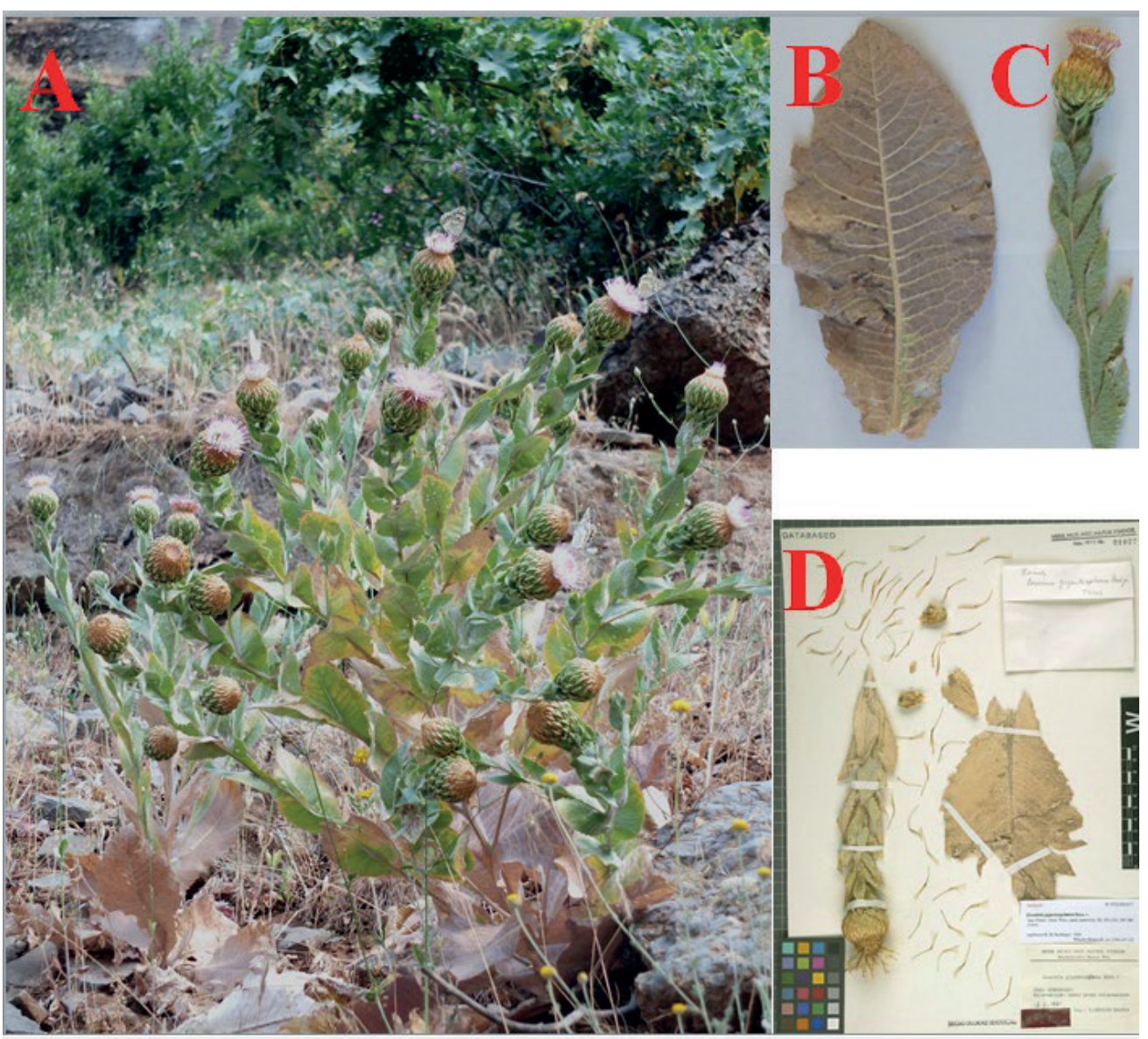

Şekil 2. Cousinia gigantosphaera bitkisinin A) Genel görünüşü, B) Taban yaprağı, C) İnfloresans, D) Tip örneği (Natural History Museum, Vienna-Herbarium W)

büyüklüğünde, araknoid tüylü. Fillariler 100'den fazla, en diştaki fillariler üst yapraklara benzerlik gösterirler fakat daha küçük yapıdadırlar. Üst üste binmiş imbrikat yapıda ve deltoid şekillidirler. Apendage 15 mm’ye kadar genişleyebilir, ucu dikenli, araknoid tüylenme gösterir. Reseptakulum tüyleri sert. Çiçekler 70-160; korolla pembe renkli (kuruyunca kirli beyaz olabilir), 28-35 mm uzunluğunda, tüp uzunluğu yaklaşı $20 \mathrm{~mm}$; lob uzunluğu yaklaşık $10 \mathrm{~mm}$, anterler hertarafi benzer renkte. Akenler $6 \times 2 \mathrm{~mm}$ ve oldukça basık bir yapıda bulunabilirler. Uzunlamasina gri-kahve renkli, çizgili ve düzensiz siyah benekli olabilir. Pappus oldukça dökülücü.

Tip: Iraq: Kurdistan: Asma near Sulaimaniyah, slope above Casino, poor oak scrub, 13.7. 1961, R. Wheeler-Hainess. n., E, Holotip (fotoğraf !), W, Isotip (fotoğraf!).

Çiçeklenme: Mayıs-Haziran

Meyvelenme: Haziran-Temmuz

Yetişme ortamı: Kayalık yamaçlar, yol kenarları

Genel yayılışı: Kuzey Irak
Materyal: Türkiye, C9 Şırnak: BeytüşşebapAyvalık köyü arası, Ayvalık’tan Beytüşşebap'a doğru 6-8. km, kayalık yamaçlar, meșe açıklıkları, $37^{\circ} 31^{\prime} 55^{\prime \prime} \mathrm{K} 43^{\circ} 06^{\prime} 42^{\prime \prime} \mathrm{D}, 1240$ m, 19.07.2019, M.Fidan, M.Pınar, H.Eroğlu MMH1710; Beytüşşebap, Feraşin yaylası yolu 6. km, kayalık yamaçlar, $37^{\circ} 55^{\prime} 26^{\prime \prime} \mathrm{K} 43^{\circ} 11^{\prime} 09^{\prime \prime} \mathrm{D} 1623 \mathrm{~m}$, 12.07.2018, M.Fidan, M.Pınar, H.Eroğlu MMH915.

Cousinia gigantosphaera, Mehregan and Kadereit (2008)'in "Systematics, Phylogeny and Biogeography of Cousinia (Asteraceae)" isimli çalıșmasında Cousinia macrolepis Boiss. \& Hausskn. taksonunun bir varyasyonu olarak ifade edilmiştir. Ancak her iki taksonun tip örneklerine bakıldığında özellikle taban yapraklarındaki farklılık ve fillarilerin durumu bu iki taksonun farklı olduğunu göstermektedir (Şekil 3). Nitekim "The International Plant Name Index (IPNI)"de her iki tür ismi geçerliliğini halen korumaktadır (Anonymous, 2019). Bundan dolay1 yeni takson Cousinia gigantosphaera olarak Türkiye florası için yeni kayıt olarak belirlenmiştir. 


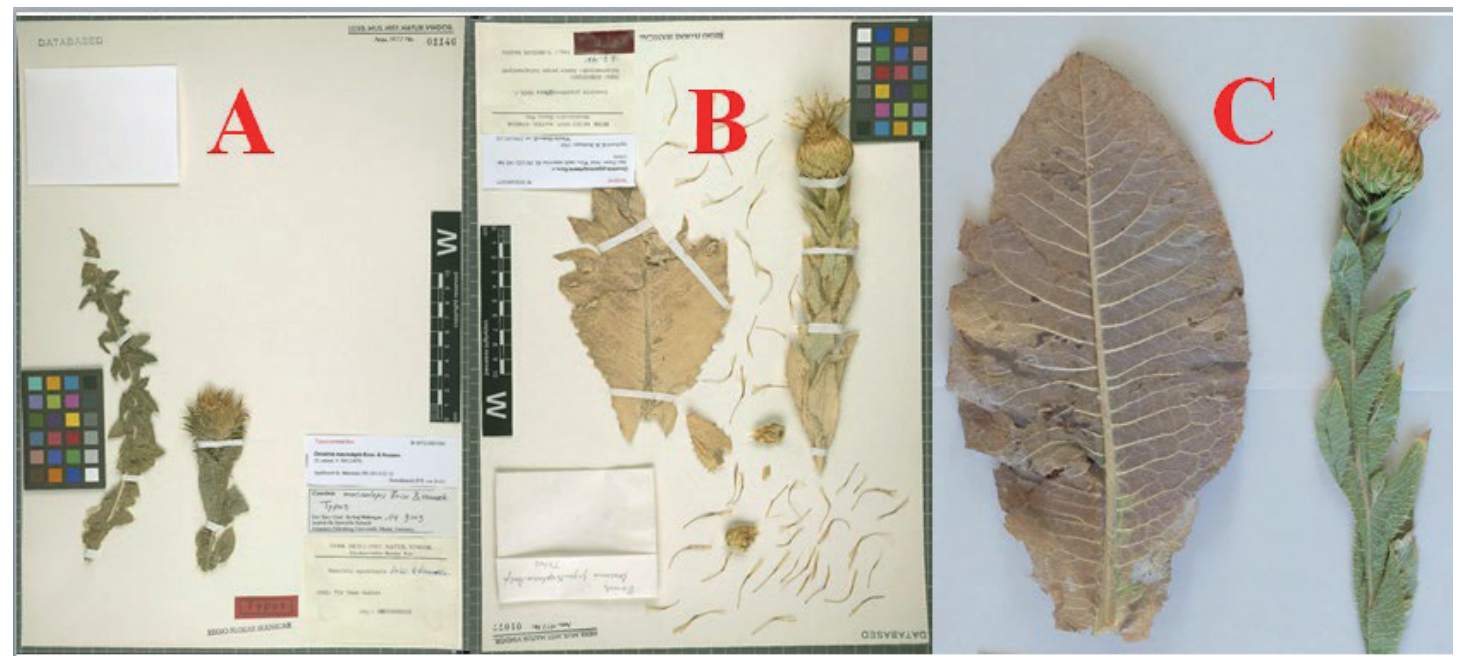

Şekil 3. A) Cousinia macrolepis tip örneği (Natural History Museum, Vienna-Herbarium W),

B) C. gigantosphaera tip örneği (Natural History Museum, Vienna-Herbarium W),

C) Bu çalışmada toplanan herbaryum örneği

\section{Sonuçlar}

$\mathrm{Bu}$ çalıșma ile Türkiye Florası'na Asteraceae (Compositae) familyasının bir üyesi olan Cousinia cinsinden yeni bir tür eklenmiştir. Böylece Türkiye Florası'nda kayıtlı olan Cousinia cinsinin tür sayısı 41'e çıkmıștır. Makalenin yayınlanması ile yeniden yazılan renkli resimli Türkiye Florası'na katkı sağlanmış olacaktır.

\section{Teșekkür}

Arazi çalışmaları esnasında bize gösterdikleri destekten dolayı T.C. Tarım ve Orman Bakanlığı, Doğa Koruma ve Milli Parklar Genel Müdürlüğü Şırnak Şubesi çalışanlarına ve Şırnak ilinin karasal ve iç su ekosistemleri biyolojik çeşitlilik envanter ve izlemesi çalışmasının yapılmasını sağlayan EKOİZ firmasına katkılarından dolayı teşekkür ederiz.

\section{Kaynaklar}

Anonim, 2019. Cousinia Cass. (https://bizimbitkiler.org. tr/yeni/demos/technical/), (Erişim tarihi: 25.07.2019).

Anonymous, 2019. Cousinia gigantosphaera Rech. f. (https://www.ipni.org/?q=Cousinia\%20gigantosphae ra), (Erişim tarihi: 25.07.2019).

Davis, P.H., Mill, R., Tan, K., 1988. Flora of Turkey and the east Aegean Islands. Vol. 10, Edinburgh University Press, Edinburgh.

Güner, A., Özhatay, N., Ekim, T., Başer, K.H.C., 2000. Flora of Turkey and the East Aegean Islands, (Supplement). Edinburgh University Press, Edinburgh.

Huber-Morath, A., 1975. Cousinia Cass. P.H. Davis (Ed.), Flora of Turkey and the East Aegean Islands, Edinburgh University Press, Edinburgh, UK, Volume 5, pp. 329-353.
İlçim, A., Özçelik, H., 1997. Cousinia boissieri Buhse ve Cousinia vanensis Hub.-Mor. (Asteraceae) türleri üzerinde morfolojik, ekolojik ve biyosistematik araştırmalar. Ot Sistematik Botanik Dergisi, 3(2): 73-88.

Mehregan, I., Assadi, M., Atar, F., 2003. Cousinia gatchsaranica, Sect. Haussknechtianae a new species from SW Iran. Willdenowia, 33(1): 107-111.

Mehregan, I., Kadereit, J.W., 2008. Taxonomic revision of Cousinia sect. Cynaroideae (Asteraceae, Cardueae). Willdenowia, 38(2): 293-362.

Moore, D.M., 1975. Cousinia Cass. T.G. Tutin and V.H. Heywood (Eds.), Flora Europea, Cambridge University Press, London, UK, Volume 4, pp. 215 216.

Post, G.E., 1933. Flora of Syria, Palestine and Sinai, American Press, Beirut.

Ranjbar, M., Negaresh, K., Karamian, R., 2012. Centaurea regia subsp. javanroudense, a new subspecies of Centaurea sect. Cynaroides (Asteraceae), from flora of Iran. Biological Diversity and Conservation, 5(1): 5-10.

Rechinger, K.H., 1964. Flora of Lowland Iraq. Verlage Von J. Cramer, Weinheim.

Rechinger, K.H., 1972. Flora Iranica. K.H. Rechinger (Ed.), Compositae-Cynereae I: Cousinia Cass., Akademishe Druck and Verlagsanstalt, Graz, Avusturya, Volume 90, pp. 1-329.

Rechinger, K.H., 1979. Flora Iranica. K.H. Rechinger (Ed.), Compositae-Cynareae III: Cousinia Cass., Akademishe Druck and Verlagsanstalt, Graz, Avusturya, Volume 139, pp. 108-153.

Sheidai, M., Mehdigholi, K., Ghahreman, A., Atar, F., 2006. Cytogenetic study of the genus Cousinia (Asteraceae, section Serratuloideae) in Iran. Genetics and Molecular Biology. 29(1): 117-121.

Tscherneva, O.V., 1962. Cousinia Cass. B.K. Shishkin (Ed.), Flora URSS, Nauka Press, Russia, Volume 4, pp. 412-422. 